\title{
Performed Clinical Study
}

National Cancer Institute

\section{Source}

National Cancer Institute. Performed Clinical Study. NCI Thesaurus. Code C70759.

A business process status of a clinical study that refers to the study that started the execution of activities specified by the study protocol. The data associated with the performed study describes quantitatively and qualitatively actual observations and events occurring in the study after its approval, such as actual accrual numbers, dates of subject enrollment, etc. 